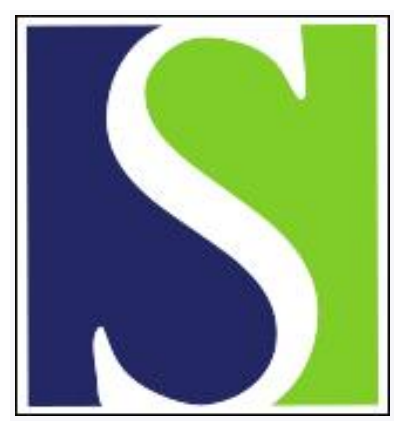

Scand J Work Environ Health 1997;23(3):193-199

https://doi.org/10.5271/sjweh.198

Issue date: Jun 1997

Short-term effect of hand-arm vibration exposure on tactile sensitivity and manual skill

by Thonnard J-L, Masset D, Penta M, Piette A, Malchaire J

Key terms: manual dexterity; mechanoreceptive unit; precision grip; pressure perception; vibrotactile perception

This article in PubMed: www.ncbi.nlm.nih.gov/pubmed/9243729

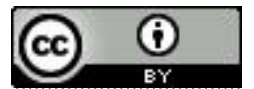




\title{
Short-term effect of hand-arm vibration exposure on tactile sensitivity and manual skill
}

\author{
by Jean-Louis Thonnard, PhD, ${ }^{1}$ Dominique Masset, ${ }^{2}$ Massimo Penta, ${ }^{1}$ Alain Piette, ${ }^{2}$ \\ Jacques Malchaire, $P h D^{2}$
}

Thonnard J-L, Masset D, Penta M, Piette A, Malchaire J. Short-term effect of hand-arm vibration exposure on tactile sensitivity and manual skill. Scand J Work Environ Health 1997;23(2):193-8.

\begin{abstract}
Objectives The present study investigated whether the impairment of tactile sensitivity after exposure to vibration disturbs the motor control of precision handling and, if so, whether it can result in an increased risk of injury during or after tasks involving the use of vibrating tools.

Methods Twelve men were manually exposed to vibration from an electric sander for $30 \mathrm{~min}$. Cutaneous sensitivity was quantified by measuring the pressure perception threshold and vibration perception threshold $(125 \mathrm{~Hz})$ on the pulp of the second finger. Manipulative skill was evaluated by grip-lift movements and the Purdue pegboard test.

Results The vibration perception threshold increased very significantly from $94.0 \mathrm{~dB}\left(0.06 \mathrm{~m} / \mathrm{s}^{2}\right)$ before the vibration exposure to $127.5 \mathrm{~dB}\left(3.2 \mathrm{~m} / \mathrm{s}^{2}\right)$ immediately after the exposure. The pressure perception threshold tended to increase after vibration exposure, although not significantly, but manipulative skill was not altered.

Conclusions Change in vibration perception threshold was not associated with a significant increase in the pressure perception threshold or a perturbation of manual skill. Therefore, in conditions similar to those of our experiment, the safety of a precision task does not appear to be reduced after such vibration exposure.
\end{abstract}

Key terms manual dexterity, mechanoreceptive units, precision grip, pressure perception, vibrotactile perception.

Psychophysical studies have reported that tactile sensitivity is impaired during and for a time after vibration exposure $(1-3)$. The pathophysiological mechanisms involved in the peripheral neural changes induced by vibration are not fully understood. Damage induced by vibration has been observed in the ultrastructure of the peripheral nerve $(4-5)$, as well as in the infraneural microvessels (6). Microneurographic recordings of impulses from single afferent nerve fibers in awake human subjects have shown that an acute but temporary depression in sensitivity occurs in skin mechanoreceptive afferent units after fairly powerful vibration exposure. It was concluded that the acute impairment of tactile sensitivity caused by vibration exposure, as observed in psychophysical studies, can probably be explained by a depression of the excitability of the mechanoreceptive afferent units (3).

Tactile sensory information from the skin of the fingers is of crucial importance in the motor control of prehensile tasks (7-9). Changes in the excitability of the mechanoreceptive afferent units should thus impair the motor skill of the hand. Consequently disturbances in the regulation of precision grip might occur both during, and for a time after, exposure to vibration. If so, it may be a contributing factor in the occurrence of accidents among craftsmen and industrial workers while interacting with vibrating tools or among workers in professions requiring excellent hand function (precision, sensibility, fine manipulation).

Few studies have considered the short-term neurological effects of exposure to vibration among normal subjects and its influence in the workplace. Hammarskjöld et al (10) have used a gross approach to study the effects of a 10-min exposure to vibration of $20 \mathrm{~m} / \mathrm{s}^{2}$ at 50 $\mathrm{Hz}$ in a population of carpenters. They observed no difference in the performance of standard tasks before and after vibration exposure. Other studies have tried to quantify the short-term neurological effects, in particular the 
impairment of the vibration perception sense, without considering the potential interference with workplace safety $(1,11-13)$.

The objective of the present research was to investigate whether the impairment of tactile sensitivity after exposure to vibration disturbs the motor control of precision handling, and, if so, whether it can result in an increased risk of injury during or after tasks involving the use of vibrating tools.

\section{Subjects and methods}

\section{Subjects and procedures}

Twelve male students participated in this study. They were given full information about the objective of the study and its protocol, and they gave their free consent to participate. The subjects were in good health, had never suffered from any neurological, vascular or traumatic problem in the upper limbs, and were not using vibrating tools on a regular basis. Their mean age, weight, and height were 24.5 (SD 2.5) years, 71.5 (SD 12.0) kg, and $175.6(8.4) \mathrm{cm}$, respectively.

The subjects set with their upper arm along their trunk, the forearm horizontal in slight abduction, the hand in the neutral position of flexion-extension and radio-ulnar deviation. They were exposed to vibration from grasping an electric sander with their dominant hand. The subjects were familiarized with the procedures before the measurements.

The sander was representative of the tools available on the market for both private and professional use. It was counterbalanced so that the subjects could hold it without supporting its weight. The vibration amplitudes were measured in the $\mathrm{X}$ (perpendicular to the hand), $\mathrm{Y}$ (the axis of the grip) and $\mathrm{Z}$ (the axis of the forearm) axes on the handle of the sander according to ISO standard

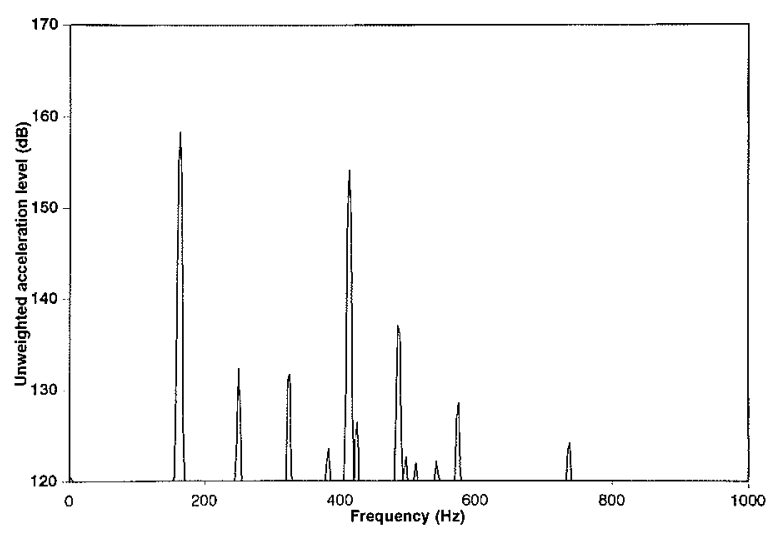

Figure 1. Spectrum for equal bandwidth $(2.5 \mathrm{~Hz})$ acceleration in the axis perpendicular to the hand ( $\mathrm{X}$ axis), as generated by an electric sander.
5349, using a Brüel \& Kjær (B \& K) (type 4321) triaxial accelerometer and $\mathrm{B} \& \mathrm{~K}$ (type 2231) sound level meter equipped with a vibration module (B \& K type 2522). The spectrum of the equal bandwidth $(2.5 \mathrm{~Hz})$ acceleration in the predominant $\mathrm{X}$ axis is shown in figure 1 ; the vibration consisted mainly of 2 sinusoidal accelerations at $162.5 \mathrm{~Hz}$ and $420 \mathrm{~Hz}$. The weighted acceleration amplitudes were equal to $9.1,2.3$ and $7.7 \mathrm{~m} / \mathrm{s}^{2}$, respectively, in the $\mathrm{X}, \mathrm{Y}$ and $\mathrm{Z}$ axes. The unweighted amplitudes were 101,55 , and $85 \mathrm{~m} / \mathrm{s}^{2}$, respectively. The vector sums of the weighted and unweighted acceleration over the 3 axes were $12 \mathrm{~m} / \mathrm{s}^{2}$ and $143 \mathrm{~m} / \mathrm{s}^{2}$, respectively. The exposure to vibration lasted $30 \mathrm{~min}$.

The tests were conducted in the following order: the vibration perception threshold, the pressure perception threshold, the grip-lift movement, the Purdue pegboard test. The whole sequence took less than 4 min and was conducted 3 times before the vibration exposure, immediately after the vibration exposure, and again after a recovery period of $25 \mathrm{~min}$.

Skin temperature was controlled on the tip of the middle finger with an Ultrakust infrared thermometer before and after the vibration exposure.

\section{Vibration perception threshold}

The vibration perception threshold was measured with a B \& K 4810 shaker that drove a metallic rod with a cross sectional area of $5 \mathrm{~mm}^{2}$. The vibrating rod was mounted on a beam balance that maintained the force applied against the skin at $0.2 \mathrm{~N}$. The vibration exciter was regulated by a Madsen Micromate 304 audiometer modified to generate sine signals at $125 \mathrm{~Hz}$ in the range of 50 to $150 \mathrm{~dB}\left(\mathrm{re} 1 \mu \mathrm{m} / \mathrm{s}^{2}\right)$.

The subject was seated, with his upper arm along the trunk and his forearm bent at $90^{\circ}$, and resting on the box on which the counterbalanced shaker was mounted. The vibration perception threshold was measured on the pulp of the second finger. The vibration level was set at $70 \mathrm{~dB}$ and then progressively increased by steps of $5 \mathrm{~dB}$. The subject was instructed to press a button with the other hand as soon as he could perceive the vibration. The level was then decreased by steps of $5 \mathrm{~dB}$ until the vibration was no longer perceived. It was then increased again, and the search for the threshold was repeated twice. The recorded threshold was the minimum value of 3 consecutive trials.

\section{Pressure perception threshold}

The pressure perception threshold was determined using a Semmes-Weinstein esthesiometer (Lafayette Instrument Company, Inc). This instrument consists of a set of 20 monofilaments of progressively larger diameters, calibrated to exert increasing peak forces when pressed and bent against the skin. The monofilaments were applied 
perpendicularly to the pulp of the second finger, and pressure was increased until the filament bent. The weights exerted by the complete set of monofilaments ranged from 0.044 to $4385 \mathrm{mN}$. Short-lasting applications $(<1 \mathrm{~s})$ were presented according to the procedure described by Bell-Krotoski (14).

\section{Grip-lift movement}

The test instrument (figure 2) used to measure grip-lift movement was similar in design to the one reported by Westling \& Johansson (15). Its weight was $220 \mathrm{~g}$ and the 2 parallel, vertical grip surfaces were covered with suede. The force perpendicular to the grip surface (grip force) and the force tangential to the surface (load force) were measured with strain-gauge transducers. The signals were sampled at $400 \mathrm{~Hz}$ with a 12-bit resolution analog-todigital converter.

The subject was instructed to grasp the test instrument between his thumb and index finger and to lift it approximately $5 \mathrm{~cm}$ above the table for about $10 \mathrm{~s}$. He was instructed to focus on maintaining the vertical position of the object. Then, he was asked to loosen his grip force slowly and let the test instrument slide through his fingers. The slippage at the end of each trial was detected by the sudden drop in load force. The coefficient of static friction between the grip surface and the skin $(\mu)$ was determined by measuring the grip force at which the object began to slip from grasp $\left(\mathrm{GF}_{\mathrm{o}}\right)(16)$ :

$$
\mu=0.5 \mathrm{LF} / \mathrm{GF}_{\mathrm{o}},
$$

the factor 0.5 being due to the fact that the load force was distributed on 2 fingers.

Johansson \& Westling (16) proposed splitting the grip-lift movement into several phases during which different time and force parameters can be determined (figure 2). During the initial phase of the grip-lift movement, the duration of the preload and the load phases was recorded. The preload phase (a) is the delay between finger contact and the onset of the increase in load force. The duration of the load phase (b) is measured from the time when the load force is positive and shows a continuous increase until the object moves from its support (ie, the load force overcomes the gravitational weight of the object). In addition, the grip-force rate (dGF/dt) and the load-force rate (dLF/dt) were computed using a \pm 5 -point numerical differentiation. The peak values of the grip and load force rates and the respective times at which they occurred were registered. The ratios between the 2 peak values $(\omega)$ and between their times of occurrence $(\tau)$ were computed. During the static phase (c), the safety margin $(\gamma)$ is calculated by subtracting the $\mathrm{GF}_{0}: \mathrm{LF}$ ratio at slip onset from the mean GF:LF ratio computed while the object is held steadily. The test was always executed 3 times in a row, and the mean values were computed.

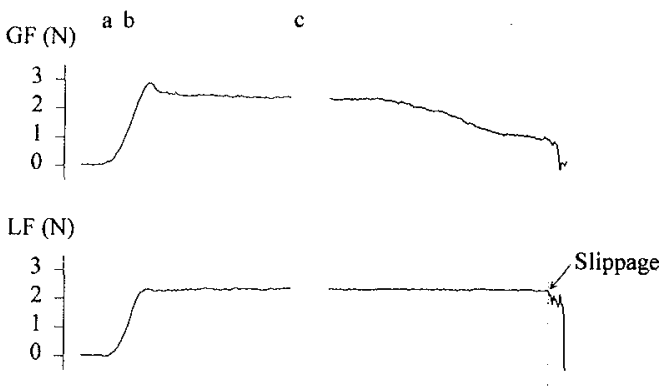

GF/LF ratio
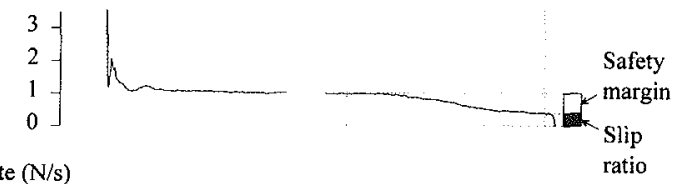

GF rate $(\mathrm{N} / \mathrm{s})$

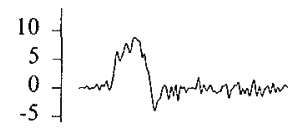

LF rate $(\mathrm{N} / \mathrm{s})$
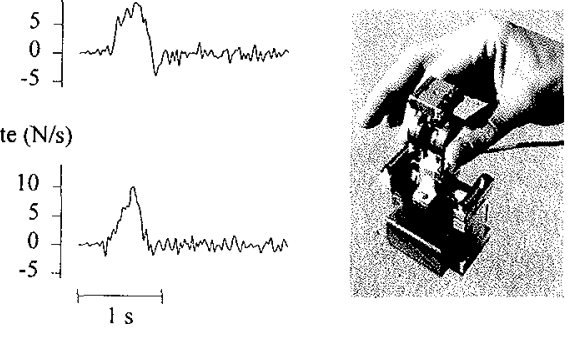

Figure 2. Grip instrument (inset) and typical traces of grip force (GF) load force (LF), the GF:LF ratio and the GF and LF rates for a subject lifting a grip instrument weighing $220 \mathrm{~g}$ with grip surfaces covered with suede. The vertical dotted lines represent the time cursors used to define the preload phase (a), the loading phase (b), the static phase (c), and the onset of slippage. Note that the peaks of the GF and LF rates reach approximately the same value and that they occur nearly simultaneously. At the end of the static phase (c), GF is slowly released until the grip instrument slides through the fingers. The slip ratio represents the GF: LF ratio at which the fingers slipped across the gripped surfaces. The white area above the slip ratio indicates the safety margin adopted to prevent slippage.

\section{Purdue pegboard}

The Purdue pegboard test (17) measures manual dexterity and emphasizes the finger dexterity factor. This factor is defined as the ability to make rapid, skillful, and controlled manipulative movements of small objects, primarily with the fingers (18).

The subjects were asked to use their dominant hand to complete only the unimanual subtest of the Purdue pegboard test. This task consists of picking up metal pegs from a cup and inserting a maximum number of them, 1 by 1 , into a row of holes within a 30 -s period.

\section{Data analysis}

For all the variables, an analysis of variance with repeated measures was conducted immediately before the exposure to vibration, immediately after the exposure, and after a recovery period of $25 \mathrm{~min}$. For each variable showing a significant effect over the repeated measure, a paired t-test was used to compare the value before the 
exposure and after the recovery period. The significance level was set at $\mathrm{P}=0.05$ for all the statistical analyses.

\section{Results}

The mean results of the tests before exposure, immediately after exposure, and after 25 min of recovery are presented in table 1 , along with the results of the statistical analyses. The vibration perception threshold increased very significantly from $94.0 \mathrm{~dB}\left(0.06 \mathrm{~m} / \mathrm{s}^{2}\right)$ before the exposure to $127.5 \mathrm{~dB}\left(3.2 \mathrm{~m} / \mathrm{s}^{2}\right)$ directly after the exposure. After a recovery period of $25 \mathrm{~min}$, the vibration perception threshold had nearly returned to normal, but was still significantly higher. The pressure perception threshold tended to increase after the exposure vibration, although not significantly. The results of the Purdue pegboard test varied significantly but clearly improved instead of decreasing after the exposure to vibration.

The effects of vibration on force coordination during precision griping were similarly investigated by comparing the parameters characterizing the grip-lift movement as described in figure 2 . The durations of the preload and load phases did not change significantly between the 3 times of measurement. The ratio between the peak values of the grip and load force rates $(\omega)$, and between their respective times of occurrence $(\tau)$, remained constant and around 1 across the consecutive trials. During the static phase of the lift, there was no statistically significant difference among the trials as far as the safety margin $(\gamma)$ and the friction coefficient $(\mu)$ were concerned. This finding indicates that (i) there was no variation in the friction between the gripped object and the glabrous skin of the fingers with time and throughout the successive lifts and (ii) that the grip force during the static phase remained perfectly matched to the friction between the grip instrument and the skin from 1 lift to another.

Skin temperature measured on the tip of the middle finger was identical before $\left(28.5 \pm 3.9^{\circ} \mathrm{C}\right)$ and after $\left(28.6 \pm 3.8^{\circ} \mathrm{C}\right)$ the vibration exposure.

\section{Discussion}

The results of this study show that exposure to vibration does not generate a short-term perturbation of manual skill even though the vibration perception threshold at a frequency of $125 \mathrm{~Hz}$ is significantly increased at the tip of the second finger. Vibrations at frequencies above $50 \mathrm{~Hz}$ selectively excite FA II units (Pacinian corpuscles), but the vibration sensation is poorly located (7) because the FA II units have large receptive fields with poorly defined borders. The role of FA II units in the motor control of precise manipulative movements remains to be clearly defined. It has been suggested that they might play a role because of their high responsiveness to mechanical transients such as those caused by an object's lift-off (7). For example, they are able to detect that an object has started to move earlier than anticipated if it is lighter than expected. Nevertheless, successful

Table 1. Results of the measurements made before the vibration exposure, immediately after the exposure, and after 25 minutes of recovery.

\begin{tabular}{|c|c|c|c|c|c|c|c|c|c|c|c|c|}
\hline \multirow[t]{2}{*}{ Variable } & \multicolumn{2}{|c|}{$\begin{array}{l}\text { Before } \\
\text { exposure }\end{array}$} & \multicolumn{2}{|c|}{$\begin{array}{l}\text { Immediately } \\
\text { after } \\
\text { exposure }\end{array}$} & \multicolumn{2}{|c|}{$\begin{array}{l}\text { After } 25 \text { min } \\
\text { of recovery }\end{array}$} & \multicolumn{3}{|c|}{ Effect of exposure } & \multicolumn{3}{|c|}{ Before versus recovery } \\
\hline & Mean & SD & Mean & SD & Mean & SD & $\begin{array}{l}\text { Degrees } \\
\text { of } \\
\text { freedom }\end{array}$ & F-value & P-value & $\begin{array}{l}\text { Degrees } \\
\text { of } \\
\text { freedom }\end{array}$ & t-value & P-value \\
\hline $\begin{array}{l}\text { Vibration perception } \\
\text { threshold (VPT) (dB) }\end{array}$ & 94.0 & 5.5 & 127.5 & 5.0 & 98.8 & 8.8 & 2 & 248.3 & $<0.001$ & 11 & 2.415 & 0.034 \\
\hline $\begin{array}{l}\text { Pressure perception } \\
\text { threshold (PPT) (mN) }\end{array}$ & 2.80 & 1.21 & 4.49 & 2.63 & 3.53 & 1.13 & 2 & 3.374 & 0.053 & - & - & - \\
\hline Purdue pegboard (n) & 16.2 & 1.8 & 17.4 & 1.8 & 17.3 & 1.6 & 2 & 12.79 & $<0.001$ & 11 & 5.087 & $<0.001$ \\
\hline Grip-lift movement & & & & & & & & & & & & \\
\hline Preload phase (ms) & 127 & 88 & 130 & 87 & 154 & 102 & 2 & 1.810 & 0.187 & - & - & - \\
\hline Loading phase (ms) & 383 & 140 & 378 & 152 & 358 & 145 & 2 & 0.746 & 0.486 & - & - & - \\
\hline $\begin{array}{l}\text { Ratio of peak values of } \\
\text { grip force and load force } \\
\text { rates }(\omega)\end{array}$ & 1.012 & 0.143 & 1.075 & 0.257 & 1.030 & 0.179 & 2 & 0.731 & 0.493 & - & - & - \\
\hline $\begin{array}{l}\text { Ratio of time to peaks } \\
\text { of grip force and load } \\
\text { force rates }(\tau)\end{array}$ & 0.953 & 0.110 & 1.067 & 0.396 & 0.939 & 0.203 & 2 & 0.961 & 0.398 & - & - & - \\
\hline Friction coefficient $(\mu)$ & 0.96 & 0.20 & 0.96 & 0.25 & 0.93 & 0.25 & 2 & 0.175 & 0.840 & - & - & - \\
\hline Safety margin $(\gamma)$ & 0.63 & 0.28 & 0.52 & 0.28 & 0.52 & 0.19 & 2 & 2.759 & 0.085 & - & - & - \\
\hline
\end{tabular}


manipulation of an object first requires its stabilization in the grip.

Grasp stability is assured by adequate forces normal to grip surfaces (grip forces) in relation to the destabilizing forces tangential to the grip surfaces (load forces). Thus it is the parallel coordination between the grip force and the load force which ensures a safe grip. It has been demonstrated that, in a lifting task, the responses in FA I afferents (Meissner corpuscles) primarily reflect changes in tangential load forces both during the preload phase and early during the loading phase ( $a$ and $b$ in figure 2 ) when the contact between the digits and the object is being established (7). Westling \& Johansson (7) have estimated that, at a grip force of $<1 \mathrm{~N}$, approximately 300 FA I afferents are engaged in each digit. The extreme sensitivity of the FA I units to tangential load forces, and their high density, may allow FA I units to play a central role in scaling reactive grip forces to imposed load forces (9).

Considering the grip-lift movement studied in our experiment, it is important to point out that the parallel coordination between the grip and the load forces was not impaired by vibration since the force and time parameters characterizing this particular movement did not change after the vibration exposure (table 1). The fact that the ratios $\omega$ and $\tau$ remained constant and around 1 indicated that the tuning of the grip and load force was similar and that this perfect coordination between the 2 forces was not affected by vibration. This finding implies that fast adaptive-type I receptors were not perturbed by vibration exposure, and that FA I afferent information generated during the lifting task was still available for the central nervous system.

The finding that pressure perception threshold was not significantly affected by vibration exposure confirms our observation that tactile sensitivity was not completely disrupted by vibration. We observed a slight increase in the pressure perception threshold which was indicative of diminished light touch. At these low threshold levels, Bell-Krotoski (14) reported that subjects may not even realize that they have a sensory impairment, yet they are able to maintain fair use of their hands. A pressure perception threshold above $7 \mathrm{mN}$ must be reached before they are faced with difficulties in manipulating objects. Pressure perception is based on signals detected by the rapidly adapting afferent units, particularly when short-lasting indentations are presented (19) as in our experiment. This circumstance indicates that either FA I, or perhaps both FA I and FA II receptors, were not diminished in their ability to detect pressure after vibration exposure.

The conclusion of a lack of relationship between the strong temporary threshold shift of the vibration perception threshold at $125 \mathrm{~Hz}$ and manual skill is further reinforced by the fact that the performances on the Pur- due pegboard test were not altered. This unimanual test involves a sequence of grip-lift movements, transfers, and positioning using a metal peg and measures unilateral fine manual dexterity (20). Instead of being degraded, the performances improved slightly, probably due to a learning effect.

\section{Concluding remarks}

The exposure to fast rotating tools for $30 \mathrm{~min}$ clearly led to a temporary threshold shift in vibration perception at a frequency of $125 \mathrm{~Hz}$ in normal subjects. A change in the vibration perception threshold was not associated with a significant increase in the pressure perception threshold or with a perturbation of motor control in precision handling. Under these conditions, the safety of a precision task may not be reduced after vibration exposure.

Our conclusions must be restricted to the experimental conditions of our study, and further research is needed to investigate whether the same results are reached when slowly rotating tools (with lower excitation frequencies) are used or when the exposure lasts longer than $30 \mathrm{~min}$.

Obviously no conclusion can be derived concerning the potential association between an inctease in the permanent vibration perception threshold in subjects exposed for many years to vibration and their manipulative performances.

\section{Acknowledgments}

We are grateful to Professor NC Heglund for providing helpful comments on this manuscript.

\section{References}

1. Lidström IM, Hagelthorn G, Bjerker N. Vibration perception in persons not previously exposed to local vibration and in vibration exposed workers. In: Brammer AJ, Taylor W, editors. Vibration effects in the hand and arm in industry. New York (NY): John Wiley \& sons, 1982:61-5.

2. Brammer AJ, Taylor W, Piercy JE. Assessing the severity of the neurological component of the hand-arm vibration syndrome. Scand J Work Environ Health 1986;12:428-31.

3. Lundström R, Johansson RS. Acute impairment of the sensitivity of skin mechanoreceptive units caused by vibration exposure of hand. Ergonomics 1986;5:687 $\longrightarrow 98$.

4. Ho ST, Yu HS. Ultrastructural changes of the peripheral nerve induced by vibration: an experimental study. Br J Ind Med 1989;46:157-64.

5. Lundborg G, Dahlin LB, Hansson HA, Kanje M, Necking LE. Vibration exposure and peripheral nerve fiber damage. J Hand Surg Am 1990;15: 346-51.

6. Lundborg G, Dahlin LB, Danielsen N, Hansson HA, Necking LE, Pyykkö I. Intraneural edema following exposure to vibra- 
tion. Scand J Work Environ Health 1987;13:326-9.

7. Westling G, Johansson RS. Responses in glabrous skin mechanoreceptors during precision grip in humans. Exp Brain Res 1987;66:128-40.

8. Johansson RS. How is grasping modified by somatosensory input? In: Humfrey DR, Freund H-J, editors. Motor control: concepts and issues. Chichester: John Wiley and Sons, 1991: $331-55$.

9. Macefield VG, Häger-Ross C, Johansson RS. Control of grip force during restraint of an object held between finger and thumb: responses of cutaneous afferents from the digits. Exp Brain Res 1996;108:155-71.

10. Hammarskjöld E, Harms-Ringdahl K, Ekholm J, Samuelson B. Effect of short-time vibration exposure on work movements with carpenters' hand tools. Int J Ind Ergon 1986;8: $125-34$.

11. Nishiyama K, Watanabe S. Temporary threshold shift of vibratory sensation after clasping a vibrating handle. Int Arch Occup Environ Health 1981;49:21-33.

12. Nishiyama K, Taoda K, Yamashita H, Watanabe S. Application of a new, self-recording, vibratory sensation meter to measure temporary threshold shift of vibratory sensation caused by local vibration exposure. Int Arch Occup Environ Health 1994;66:97-102.

13. Harada N, Griffin MJ. Factors influencing vibration sense thresholds used to assess occupational exposures to hand transmitted vibration. Br J Ind Med 1991;48:185-92.

14. Bell-Krotoski JA. Light touch-deep pressure testing using the Semmes-Weinstein monofilaments. In: Hunter JM, Schneider LH, Mackin EJ, Callahan AD, editors. Rehabilitation of the hand: surgery and therapy. St Louis (MO): Mosby, 1990: 585-93.

15. Westling G, Johansson RS. Factors influencing the force control during precision grip. Exp Brain Res 1984;53:277-84.

16. Johansson RS, Westling G. Roles of the glabrous skin receptors and sensorimotor memory in automatic control of precision grip when lifting rougher or more slippery objects. Exp Brain Res 1984;56:550—64.

17. Tiffin J, Asher EJ. The Purdue Pegboard: norms and studies of reliability and validity. J Appl Psychol 1948;32:234-47.

18. Fleishman EA, Ellison GD. A factor analysis of fine manipulative tests. J Appl Psychol 1962;46:96-105.

19. Johansson RS, Vallbo ÅB, Westling G. Thresholds of mechanoreceptive afferents in the human hand as measured with von Frey hairs. Brain Res 1980;184:343-51.

20. Desrosiers J, Hebert R, Bravo G, Dutil E. The Purdue Pegboard test: normative data for people aged 60 and over. Disability Rehabil 1995;17:217-24.

Received for publication: 22 August 1996 